\title{
Anatomical and functional subdivision within the primate lateral prefrontal cortex
}

\author{
MATTHEW F. S. RUSHWORTH \\ University of Oxford, Oxford, England
}

\begin{abstract}
It has been suggested that there is specialization of function within the lateral prefrontal cortex; it has been argued that the ventral and dorsal divisions of the prefrontal cortex are concerned with the processing of form and spatial information, respectively. The evidence for such a division of function is reviewed. According to an alternative view, the dorsal prefrontal cortex is better thought of as playing a high-level role within the context of the motor system; this is consistent with the fact that it is this part of the prefrontal cortex that is connected with lateral and medial premotor areas, the parietal cortex, and the cerebellum and that it is this part of the prefrontal cortex that is concerned with action selection and attention to action. The ventral prefrontal cortex, on the other hand, has widespread connections with sensory cortices and may be essential for stimulus selection and sensory attention; this may underlie its role in arbitrary or conditional associations involving diverse stimuli.
\end{abstract}

Every year physiologists and anatomists reparcel the primate temporal and parietal lobes into ever smaller divisions. Each region has its own distinctive pattern of neuronal activity and anatomical connections that allows it to make its own individual contribution to the cognitive life of the brain's owner. The frontal lobes stand as something of an affront to the subdividers' project, because there is so little agreement about what the basic component processes of the frontal lobes might be (Roberts, Robbins, \& Weiskrantz, 1998).

It is less contentious to suggest that we can draw basic distinctions between the lateral and the ventral surfaces of the prefrontal cortex (see, e.g., Dias, Robbins, \& Roberts, 1996; Roberts, 1996). Perhaps the most influential theory of lateral prefrontal function has concerned its role in holding (Goldman-Rakic, 1987, 1998) and manipulating (Petrides, 1998) information in working memory. In people, working memory deficits after lateral prefrontal lesions can be distinguished from deficits in the affective control of behavior caused by lesions of the ventromedial prefrontal cortex (Bechara, Damasio, Tranel, \& Anderson, 1998). Neuroimaging studies also suggest a similar role for the human ventromedial prefrontal cortex (Elliott, Frith, \& Dolan, 1997, 1999). In the monkey, a high proportion of ventromedial prefrontal cells are concerned with learning about potential rewards and punishments (Rolls, 1999), and lesions here disrupt a monkey's ability to learn which one of a pair of objects is rewarded (Baylis \& Gaffan, 1991). What is not so clear, however, is whether there are any functional subdivisions

This research was supported by the Royal Society. Correspondence concerning this article should be addressed to M. F. S. Rushworth, Department of Experimental Psychology, University of Oxford, South Parks Road, Oxford OX1 3UD, England (e-mail; matthew.rushworth@ psy.ox.ac.uk). to be found within the large expanse of the lateral prefrontal cortex.

\section{Working Memory and Regional Specialization Within the Lateral Prefrontal Cortex}

Any reference to working memory must be prefaced by acknowledgement of the confusion that has surrounded the term. The following discussion of working memory will be restricted to the more limited sense of retention of information through short delays in order to guide subsequent action (Goldman-Rakic, 1987). This hypothesis is distinct from the more complicated set of processes that include "executive control," manipulation of information, the control of attention, and short-term memory that have been subsumed under the heading of working memory by authors such as Baddeley and Hitch (1974).

According to Goldman-Rakic's (1998) domain-specific theory of prefrontal function, different regions of the lateral prefrontal cortex are concerned with holding different types of information. Whereas the ventral lateral prefrontal cortex (VLPFC) is concerned with holding information about forms, the dorsolateral prefrontal cortex (DLPFC) is concerned with holding information about spatial locations. Two principle lines of evidence have been adduced in support of this model.

First, it has been argued that the DLPFC and the VLPFC are distinguished by their anatomical connections with the parietal and the temporal lobes, respectively (Petrides \& Pandya, 1984). An influential account of parietal and temporal lobe specialization (Ungerleider \& Mishkin, 1982) maintains that these regions are relatively specialized for processing spatial and object-related information, respectively. It was therefore argued that the specializations of the parietal and temporal lobes might be carried forward into the DLPFC and the VLPFC. The attractively simple picture of temporal-VLPFC and parietal-DLPFC 
systems should be revised by demonstrations that the anatomical connections are not so clearly segregated; there are some connections between some more posterior parts of the VLPFC and the parietal lobe (Cavada \& Goldman-Rakic, 1989; Schall, Morel, King, \& Bullier, 1995). Nevertheless, despite these equivocations, hypotheses of temporal/parietal specialization can still inform hypotheses of VLPFC/DLPFC specialization.

The second line of evidence is based on claims that monkey lesion and cell recording studies and human neuroimaging studies have demonstrated dorsal and ventral specializations for processing spatial and form information, respectively. The human neuroimaging literature will be briefly reviewed before considering the results of cell recording experiments performed with monkeys. Rushworth and Owen (Owen 1997; Rushworth, Nixon, Eacott, \& Passingham, 1997; Rushworth \& Owen, 1998) have reviewed this evidence and have argued that it is not always persuasive. For example, Figure 1 summarizes activations recorded in human neuroimaging studies of object/form or spatial working memory tasks published before 1998. It is clear that there is no dorsal/ ventral distinction between spatial and form tasks. The

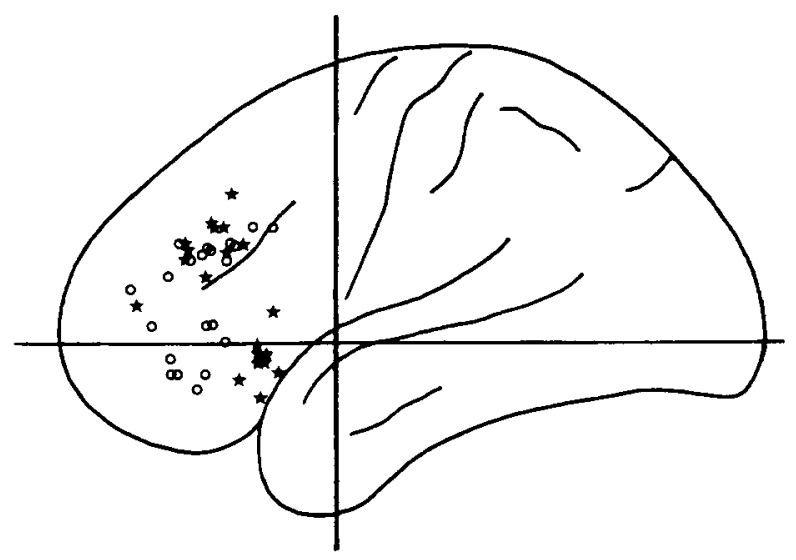

Figure 1. The location of peak activations in spatial working memory tasks (filled shapes, $\star$ ) and form working memory tasks (unfilled shapes, $O$ ) projected onto a lateral diagram of a human brain. Activation peaks recorded in both the left and the right hemispheres are shown on the same diagram. It is clear that spatial working memory tasks activate both the ventrolateral prefrontal cortex (VLPFC) and the dorsolateral prefrontal cortex (DLPFC) and that form working memory tasks activate both the VLPFC and the DLPFC. The DLPFC and the VLPFC are not distinguished by any relative specialization for holding spatial or form information in working memory. There is, however, some evidence for a rostral/caudal division between form- and spatialprocessing cortex within the VLPFC; tasks that require subjects to hold form-related information in working memory tend to produce activations that are rostral to the activations recorded in spatial working memory tasks. From "The Functional Organization of the Lateral Frontal Cortex: Conjecture or Conjuncture in the Electrophysiology Literature?" by M. F. S. Rushworth and A. M. Owen, 1998, Trends in Cognitive Sciences, 2, pp. 46-53. Copyright 1998 by Elsevier Science. Reprinted with permission. only evidence that form and spatial information processing is segregated within the prefrontal cortex is that there may be a rostral/caudal division within the VLPFC (Figure 1). Possibly related rostral/caudal transitions have recently been observed in macaque single-unit cell recordings (White \& Wise, 1999). Rainer, Asaad, and Miller (1998a) have also emphasized a more prevalent spatial signal in the posterior prefrontal cortex. Human neuroimaging studies have shown that there may also be a dorsal region just in front of the frontal eye fields, outside of what is classically considered the DLPFC, that is specialized just for spatial working memory tasks (Courtney, Petit, Maisog, Ungerleider, \& Haxby, 1998). What may be an analogous part of the macaque brain, in the anterior part of area 8 , has also been shown to contain cells with delay activity (Chafee \& Goldman-Rakic, 1998).

On turning to the monkey single-unit recordings studies that have examined DLPFC/VLPFC specializations for form and spatial processing, it is clear that the experiments have produced inconsistent results that are difficult to reconcile. On the basis of single-unit recording studies, it has been claimed that there is evidence both for (O'Scalaidhe, Wilson, \& Goldman-Rakic, 1997, 1999; Wilson, O'Scalaidhe, \& Goldman-Rakic, 1993) and against (Fuster, Bauer, \& Jervey, 1982; Rao, Rainer, \& Miller, 1997) anatomical segregation within the prefrontal cortex. A similar dichotomy of opinion exists when one considers monkey lesion studies (Levy \& Goldman-Rakic, 1999; Petrides, 1995; Rushworth, Nixon, et al., 1997). The debate has been reviewed at length before (Rushworth \& Owen, 1998), and rather than detaining ourselves with it further, it may be better to summarize: There may be some segregation of function between the dorsal and the ventral prefrontal cortices, but if there is, its basis and guiding principle remain unclear. The next section considers an alternative proposal for functional specialization within the lateral frontal cortex.

\section{A Reevaluation of the Importance of the Lateral Prefrontal Cortices' Anatomical Connections with the Parietal and Temporal Lobes}

The inference from the lateral prefrontal cortex's connections with the temporal and parietal lobes to domainspecific processing within the prefrontal cortex is itself based on a particular conception of parietal and temporal lobe function (Ungerleider \& Mishkin, 1982). Ungerleider and Mishkin argued that the parietal and temporal lobes were the destinations of two streams of visualprocessing areas. It was claimed that the dorsal stream, which projects to the parietal cortex, was concerned with visuospatial processing, whereas the ventral stream, which projects to the temporal lobe, was concerned with visual form discrimination. The theory had broad explanatory power and, as a result, has been one of the most influential in cognitive neuroscience. Nevertheless, it has been challenged. For the present argument, what is at issue is not 
whether it is perhaps more realistic to consider whether the two streams are further subdivided (Van Essen \& De Yoe, 1995; Young, 1992) or whether they are not strictly serial (Hupe, James, Payne, \& Lomber, 1998). Instead, what is at issue is the precise nature of the functional specializations of the parietal and temporal lobe areas. Goodale and Milner (1992; Milner \& Goodale, 1995) argued that the functional distinction between the parietal and the temporal lobes was not to be conceived of in terms of specializations for processing different kinds of visual information but in terms of specializations for processing visual information for different purposes; they argued that the ventral and the dorsal visual streams were specialized for using visual information for object identification and for movement guidance, respectively.

At first, the theoretical difference seems subtle, but it has important ramifications. Some of the visually responsive areas of the parietal cortex, such as the lateral intraparietal area (LIP) are now known to contain cells with activity rates that are modulated by visual shapes (Sakata et al., 1999; Sereno \& Maunsell, 1998). Such a finding is difficult for a theory based on the distinction between form and spatial vision (Ungerleider \& Mishkin, 1982), but it can be accommodated by a theory based on a distinction between vision for identification and vision for action (Milner \& Goodale, 1995). As Milner and Goodale point out, visual forms are not just important for helping us to distinguish between objects. They also determine the manner in which movements are made; grasping and other hand movements are shaped by the visual form of the objects that are targeted. Moreover, the ability of both people and monkeys to use visual form information to preshape hand movements is lost after parietal lesions (Perenin \& Vighetto, 1988; Rushworth, Nixon, \& Passingham, 1997).

If the temporal and parietal lobes are not defined by the type of information that they process, it seems unlikely that different parts of the prefrontal cortex, with which they are interconnected, will be domain-specific processing areas for form and space. Instead, the relative specializations of the VLPFC and the DLPFC are more likely to reflect the temporal and parietal lobes' respective concerns of stimulus identification and action guidance and selection. In order to achieve these goals, visual information that is either form related or spatial will be processed by either lateral prefrontal region.

In this section, it was considered whether the VLPFC and the DLPFC were specialized for form and spatial working memory. If, however, the VLPFC and the DLPFC are preferentially interconnected with the temporal and the parietal lobes, respectively, then, according to Milner and Goodale's (1995) theory, we should expect the VLPFC and the DLPFC to be preferentially involved in visual identification and movement, respectively. In the next section, it will be considered whether a DLPFC specialization for movement-related processes and a VLPFC specialization for visual identification processes is con- sistent with our current knowledge of the other connections of the prefrontal cortex of the monkey.

\section{Other Anatomical Connections of the Prefrontal Cortex}

When we move beyond just the temporal and parietal lobes and consider a wider view of the lateral prefrontal cortex's connections, it is clear that the most distinguishing feature of the DLPFC is not just that it is connected with the dorsal visual stream, but that it is connected with motor regions of the brain. Although the DLPFC does not project directly to the primary motor cortex (M1), when we consider its projections to the premotor areas (on both the lateral and the medial surface) and to the cerebellum, a clear pattern emerges: The DLPFC's connections with the parietal lobe are just one of the many that the DLPFC has with motor-related brain structures.

The sulcus principalis region of the macaque DLPFC projects to three motor areas on the medial surface of the frontal lobe (Bates \& Goldman-Rakic, 1993; Lu, Preston, \& Strick, 1994): the presupplementary motor area (preSMA) and the most anterior parts of the supplementary motor area (SMA), the rostral cingulate motor area (CMAr) and the ventral cingulate motor area (CMAv). Although the pre-SMA itself has no direct connections with the spinal cord, the adjacent SMA has many, and it is connected with M1 (Dum \& Strick, 1996; He, Dum, \& Strick, 1995; Lu et al., 1994). Parts of the cingulate motor areas, CMAr and CMAv, have connections with anterior gyral parts of M1 and with the spinal cord (Dum \& Strick, 1993, 1996; He et al., 1995; Lu et al., 1994). The VLPFC shares none of these connections (Morecraft \& Van Hoesen, 1993; Van Hoesen \& Morecroft, 1993; Van Hoesen, Morecraft, \& Vogt, 1993).

The sulcus principalis region of the macaque DLPFC also projects to the motor areas on the lateral surface of the frontal lobe: the dorsal premotor cortex (PMd) and the ventral premotor cortex (PMv). Again both these regions, or at least parts of them, have connections with M1 and the spinal cord (Dum \& Strick, 1991; Galea \& Darian-Smith, 1994; He, Dum, \& Strick, 1993). The VLPFC has no connection with the PMd. The issue of whether the VLPFC has connections with the PMv is not clear. Pandya and Yeterian's (1998) diagrams indicate that there may be some VLPFC-to-PMv connections, but other studies suggest that the origin of the lateral prefrontal connections with the PMv is restricted to the principalis region of the DLPFC (Luppino, Govoni, \& Matelli, 1998; Matelli, Camarda, Glickstein, \& Rizzollatti, 1986). Carmichael and Price (1995) claimed that the VLPFC does not have direct PMv connections, but they did find evidence of connections from the adjacent ventromedial frontal area $(12 \mathrm{~m})$ to the PMv.

The DLPFC is also interconnected with subcortical motor structures. It projects to the superior colliculi (Goldman \& Nauta, 1976), which are concerned principally with eye movements, but may also play a role in directing limb 


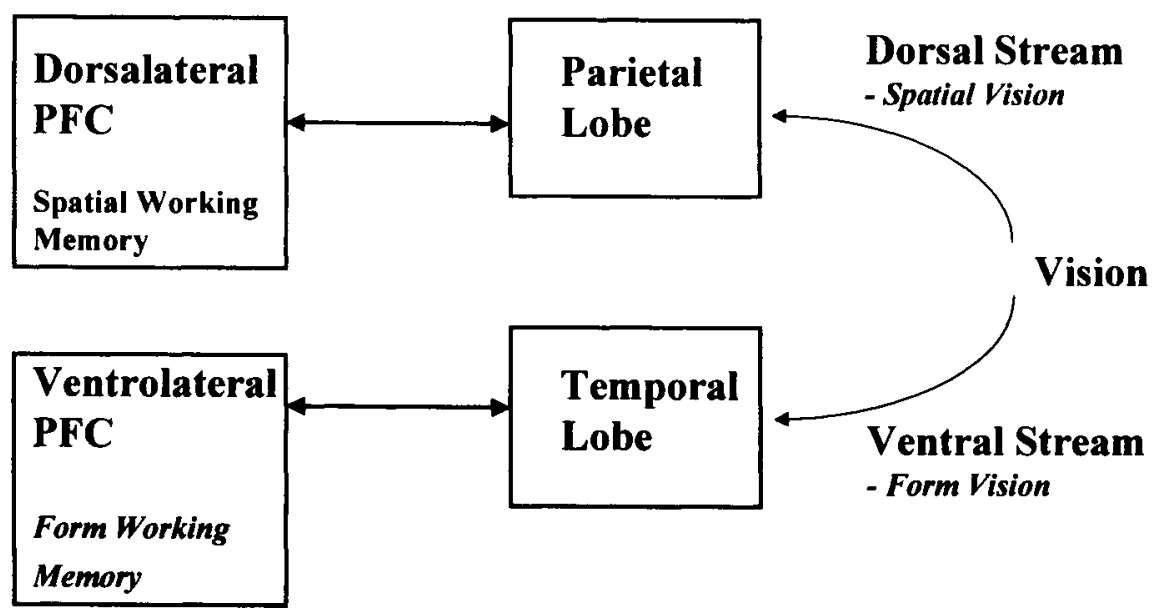

Figure 2. Summary diagram of the traditional conception of the anatomical connections of the lateral prefrontal cortex with the temporal and parietal lobes. The dorsolateral prefrontal cortex (DLPFC) is connected with the dorsal visual stream and the parietal cortex. The ventrolateral prefrontal cortex (VLPFC) is connected with the ventral visual stream and the temporal lobe.

movements (Stuphorn, Hoffmann, \& Miller, 1999; Werner, Hoffmann, \& Dannenberg, 1997). Finally, it is just the DLPFC, and not the VLPFC, that projects to the cerebellum via the pons (Middleton \& Strick, 1998; Schmahmann \& Pandya, 1997).

Instead of motor connections, the VLPFC has access to a range of highly processed sensory information. Most noticeable is the manner in which the VLPFC is interconnected with the visual and auditory modalities; these are probably the most important senses for object identification in primates. There are strong connections between the anterior VLPFC and the inferotemporal visual cortex (Carmichael \& Price, 1995; Pandya \& Yeterian, 1998; Webster, Bachevalier, \& Ungerleider, 1994). A slightly more posterior division of the VLPFC is interconnected with the auditory superior temporal gyrus (Pandya \& Yeterian, 1998). It is also the VLPFC that is interconnected with the perirhinal cortices of the temporal lobe, which have a particularly important role in representing knowledge about objects (Murray \& Bussey, 1999 ) in several modalities (Suzuki, Zola-Morgan, Squire, \& Amaral, 1993).

In conclusion, a reconsideration of the specializations of dorsal and ventral visual stream areas (Milner \& Goodale, 1995) suggests that the DLPFC and the VLPFC are specialized for motor- and sensory-related processes, respectively. A broader consideration of the anatomical connections of the two areas is consistent with this hypothesis; the DLPFC is interconnected with many premotor areas and subcortical motor structures, such as the cerebellum, whereas the VLPFC has access to information regarding object identity from several modalities via its connections with the temporal lobe. The anatomical connections of the lateral frontal lobe are summarized in Figures 2 and 3.

\section{Sensory Versus Motor Learning in the Lateral Frontal Lobes}

The last section reviewed the anatomical evidence for VLPFC's and DLPFC's interconnections with sensoryand motor-related brain regions, respectively. This section reviews neuroimaging evidence as to whether the VLPFC and the DLPFC are relatively specialized for sensory- or motor-related processes.

It has been argued that the prefrontal cortex is specialized for only certain types of mnemonic task, such as working memory tasks, in which various items of information must be stored for short periods of time (GoldmanRakic, 1998). In the case of the VLPFC, however, it is clear that lesions impair the learning of tasks with no delay element while having little effect on monkeys' abilities to hold information for short periods of time (Murray, Bussey, \& Wise, in press; Parker \& Gaffan, 1998; Passingham, 1972; Rushworth, Nixon, et al., 1997). Some authors have gone so far as to suggest that the prefrontal cortex is best considered as a "last-ditch general learning mechanism" for learning tasks that cannot be managed by the various, more specialized learning mechanisms of the medial temporal lobe (Gaffan, 1994). This perspective suggests that it might be useful to consider not whether lateral frontal regions are specialized for spatial or object-based working memory (Figure 1), but whether they are specialized for learning difficult sensory or motor tasks (Figure 4). 
In several human neuroimaging studies, changes in brain activation were investigated while subjects learned sequences of movements (Grafton, Hazeltine, \& Ivry, 1995; Hazeltine, Grafton, \& Ivry, 1997; Honda et al., 1998; Jueptner et al., 1997; Sakai et al., 1998; Toni, Schluter, Josephs, Friston, \& Passingham, 1999), and all recorded activation in the DLPFC in the region of the middle frontal gyrus. A ventral prefrontal peak was also recorded in one study (Toni et al., 1999). There is a comparable dearth of neuroimaging studies of perceptual learning, and some of those that exist did not include any scanning of the frontal lobes (Poldrack, Desmond, Glover, \& Gabrieli, 1998) but, instead, concentrated on the more posterior visual areas that are known to play a role in visual learning (Walsh, Ashbridge, \& Cowey, 1998). Two perceptual-learning studies that did scan the prefrontal cortex, however, both found a number of activation peaks in the VLPFC, but just one activation change in the DLPFC (Petersson, Elfgren, \& Ingvar, 1999; Schiltz et al., 1999). In conclusion, it is mainly the DLPFC that is recruited in motor-learning tasks but the VLPFC that is recruited in perceptual-learning tasks (Figure 4).

\section{Attention in the Lateral Frontal Cortex}

Although it is possible to use perceptual- and motorlearning tasks to distinguish the functions of the VLPFC and the DLPFC, this does not mean that these regions are only important during the learning of new tasks. It seems as if it is only necessary to require subjects to attend to their movements for activation to appear in the DLPFC. Jueptner et al. (1997) asked their subjects to perform a previously learned motor sequence in one of two ways. In one case, subjects were simply asked to perform the sequence, but in a second condition, they were asked to pay attention to what they were doing. There was significantly more activity in the DLPFC when the movements were attended. Other studies in which subjects pay attention to even single, simple finger movements also result in activation of the DLPFC (Krams, Rushworth, Deiber, Frackowiak, \& Passingham, 1998; Rushworth, Krams, \& Passingham, in press). In monkeys, the activity of DLPFC cells is modulated during the preparation of a response (Fuster, 1995; Hasegawa, Sawaguchi, \& Kubota, 1998).

It might be argued that when subjects are attending to actions, they are really just attending to the spatial destinations of the actions. All of the studies described above, however, involve just finger movements, and it is not clear that subjects code such simple movements spatially. The review of studies in Figure 1 confirms that the DLPFC is not distinguished by a special role in processing spatial information. Perhaps the most persuasive demonstration

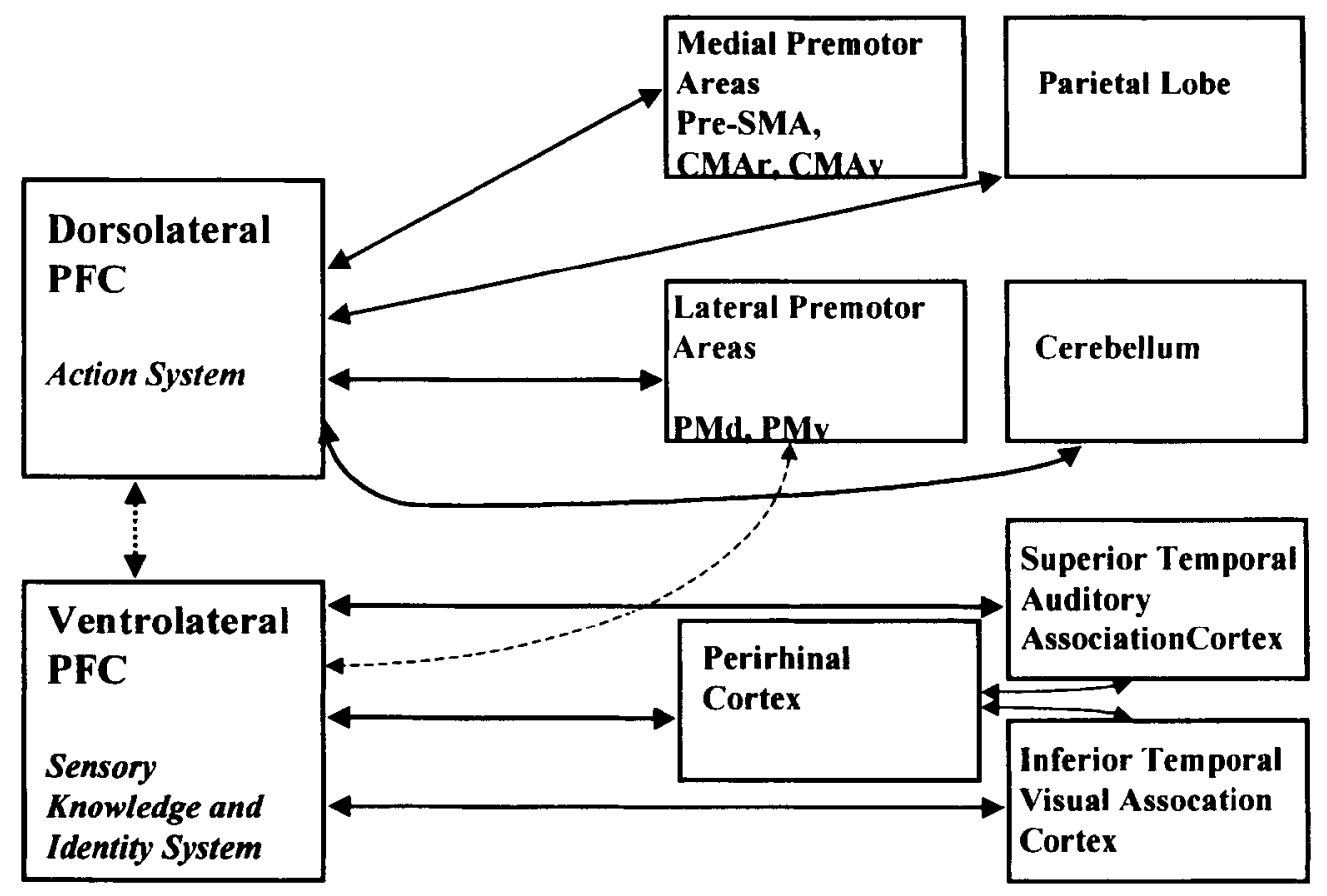

Figure 3. Summary diagram of the anatomical connections of the lateral prefrontal cortex with the motor association cortex, the cerebellum, and the sensory association cortex. From this broader perspective, it can be seen that the connection of the dorsolateral prefrontal cortex (DLPFC) with the parietal lobe is just one of the many connections between the DLPFC and the motor areas of the brain. In addition, it is clear that the connection of the ventrolateral prefrontal cortex (VLPFC) with the inferior temporal lobe is just one of the connections of the VLPFC with sensory association cortices concerned with object knowledge and identification. Pre-SMA, presupplementary motor area; CMAr, rostral cingulate motor area; CMAv, ventral cingulate motor area; PMd, doral premotor cortex; PMv, ventral premotor cortex. 


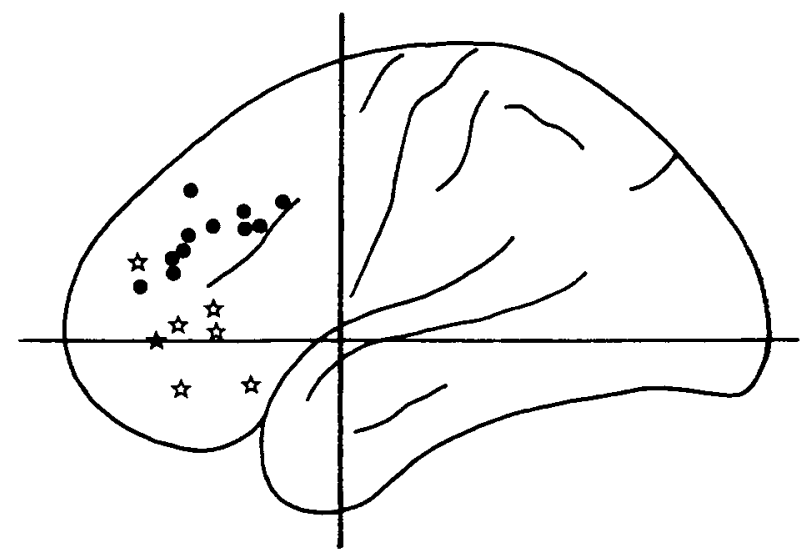

Figure 4. The location of peak activations in motor-learning tasks is shown with filled circles ( $($ ), and the location of peak activations in perceptual-learning tasks are shown with unfilled stars ( $(t)$ ). There is a predominance of dorsolateral prefrontal cortex (DLPFC) activation when subjects are learning motor tasks (Grafton, Hazeltine, \& Ivry, 1995; Hazeltine, Grafton, \& Ivry, 1997; Honda et al., 1998; Jenkins, Brooks, Nixon, Frakowiak, \& Passingham, 1994; Jueptner et al., 1997; Sakai et al., 1998; Toni, Schluter, Josephs, Friston, \& Passingham, 1999), but a predominance of ventrolateral prefrontal cortex (VLPFC) activation when subjects are learning perceptual tasks (Petersson, Elfgren, \& Ingvar, 1999; Schiltz et al., 1999).

that the DLPFC is not just concerned with the spatial dimension of a movement comes from a monkey lesion experiment. Passingham (1978) taught monkeys to press a single button repeatedly until a light was turned off. The monkeys were then required to reproduce approximately the same number of movements on the same button. DLPFC lesions impaired the monkeys' ability to perform the task even when there was no delay interposed between the end of the first movement sequence and the start of the second movement sequence. The results can be explained if the DLPFC lesions prevented the monkeys from attending to their own movements.

Conversely, it seems as if tasks requiring subjects to attend to the visual features of objects result in more ventral activation in the VLPFC. For example, Konishi et al. (1998) recorded activity in the inferior frontal sulcus as subjects switched the focus of their attention between the color and the form of stimuli. When Sakagami and Niki (1994) trained their monkeys to perform a similar task, they found that the cue-related activity of VLPFC cells depended on which dimension of the cue was currently behaviorally relevant - that is, cells' activity depended on whether the cue was red or green when color was the relevant dimension but depended on whether the cue was a circle or a cross when cue shape was the relevant dimension or on whether the cue was on the left or the right when cue position was the relevant dimension. Rainer et al. (1998a, 1998b) similarly reported that the visual activity of prefrontal neurons was influenced not just by the identity and location of stimuli presented in a visual array, but also by which stimuli and locations were cur- rently the focus of attention. Moreover, they also reported that the visual activity of some cells was unaffected by the presence or absence or the position of unattended stimuli. Rainer et al. (1998a) provide only a brief account of the anatomical location at which they recorded, but their Figure 1 suggests that the cells that they were recording from were mainly below the principal sulcus in the VLPFC. Face stimuli are very salient stimuli for both monkeys and people, and in this case, it seems that there is less doubt that they are preferentially processed in the VLPFC of both species, even outside the context of any working memory task (Courtney et al., 1998; Haxby et al., 1994; O'Scalaidhe et al., 1997, 1999).

\section{Action Selection in the Lateral Frontal Cortex}

The frontal lobes are required when actions are to be selected, particularly when the action must be selected in an unusual or nonroutine situation or when the rules guiding the selection have to be learned. Once again, it is possible to find some evidence for regional segregation within the lateral frontal cortex when we compare two different types of action selection tasks, often referred to as willed action and conditional motor selection tasks.

In the willed action, or free selection, task, subjects are allowed to freely choose any response, often out of a

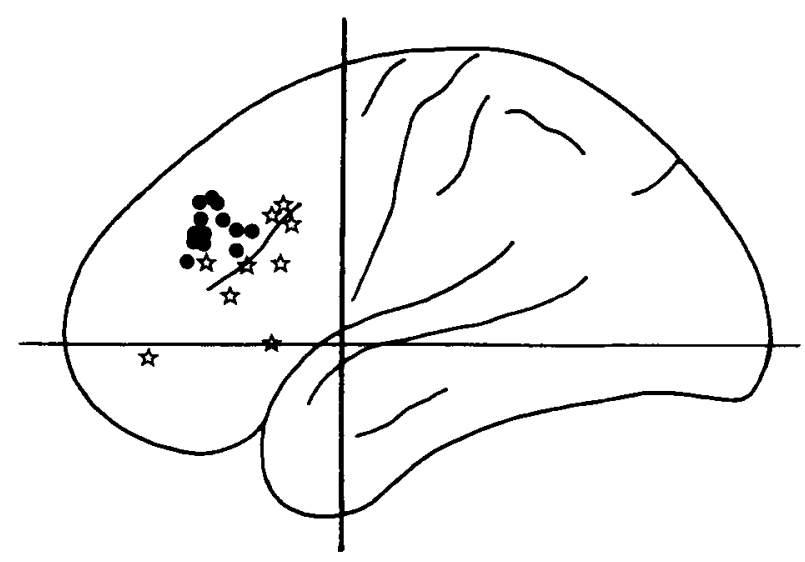

Figure 5. The location of peak activations during action selection tasks. Filled circles $(O)$ indicate the activation peaks when subjects are performing willed action tasks in which they have a free choice between many responses (Deiber, Ibanez, Sadato, \& Hallet, 1996; Deiber et al., 1991; Frith, Friston, Liddle, \& Frackowiak, 1991; Hyder et al., 1997; Jahanshahi et al., 1995; Jueptner, Jenkins, Brooks, Frackowiak, \& Passingham, 1996; Spence et al., 1997; Spence Hirsch, Brooks, \& Grasby, 1998). Unfilled stars $(\xi)$ indicate activation peaks when subjects are performing conditional motor tasks (Deiber et al., 1997; Paus, Petrides, Evans, \& Meyer, 1993; Toni \& Passingham, 1999; Toni, Schluter, Josephs, Friston, \& Passingham, 1999). There is a dorsal/ventral distinction between the two types of activations. In general, the activations recorded in the conditional task, which involves learned visuomotor associations, are situated in the vicinity of the inferior prefrontal sulcus, between the visual-learning peaks in the ventrolateral prefrontal cortex (VLPFC) (Figure 4) and the motor-learning and willed action peaks in the dorsolateral prefrontal cortex (DLPFC) (this figure and Figure 4). 
limited predefined set on any trial. In different versions of the task, subjects may make verbal responses or limb movement responses. Because there is some evidence that different prefrontal regions are activated when responses are made in different modalities (Hyder et al., 1997), Figure 5 shows only those activations recorded when subjects are performing free selection tasks in which the forelimb is used to make the response. When subjects are choosing between which finger to move, which way to move a joystick, or when to move, there is activation in the DLPFC (Deiber, Ibanez, Sadato, \& Hallet, 1996; Deiber et al., 1991; Frith, Friston, Liddle, \& Frackowiak, 1991; Hyder et al., 1997; Jahanshahi et al., 1995; Jueptner, Jenkins, Brooks, Frackowiak, \& Passingham, 1996; Spence et al., 1997; Spence, Hirsch, Brooks, \& Grasby, 1998).

In many of these tasks, the requirement to choose freely between responses is confounded with the working memory demands of remembering what responses have recently been made; for many subjects, a lack of repetition is implicit in their idea of what constitutes a random sequence. In a recent study (Hadland, Rushworth, Passingham, Jahanshahi, \& Rothwell, 1999), we showed that the performance of a free selection task that had no working memory requirement was still impaired by repetitive transcranial magnetic stimulation (rTMS) over the DLPFC. Subjects were required to press eight buttons, arranged one under each finger, in any order they chose without making any repetitions. In front of the subjects was a monitor with a display of eight circles corresponding to the positions of the eight fingers. The circles changed color as each movement was made. In this way, a record of which movements had already been made was continuously presented to the subjects. Even in this situation, DLPFC rTMS slowed the selection of movements, even those made at the beginning of a new sequence.

It is not entirely clear what role the DLPFC plays in willed action tasks. It is possible that it may play an essential role in generating the responses. Frith (in press) has argued that its importance increases as the range of possible responses increases. It may be useful to think of the DLPFC as the highest level in the motor system that is recruited during nonroutine, novel, or attention-demanding tasks. The DLPFC may be activated in the free selection task because the subject is considering and choosing between representations of the whole range of motor responses that are possible.

The conditional paradigm is quite distinct from the willed action paradigm. A person or monkey performing a conditional task has to learn particular rules about which response is to be made when each of a set of stimuli is presented. For example, a monkey might be taught to pull a joystick on seeing a red stimulus but to turn the joystick on seeing a blue stimulus. Removal of the VLPFC in monkeys impairs performance of such tasks (Murray et al., in press; Parker \& Gaffan, 1998; Passingham, Toni, \& Rushworth, in press). Cellular activity in the VLPFC is modulated while monkeys learn and perform tasks involving conditional associations (Asaad, Rainer, \& Miller, 1998; Boussaoud \& Wise, 1993a, 1993b; White $\&$ Wise, 1999). Figure 5 shows that when people learn new sets of conditional rules or when they perform conditional response selection tasks, there is activity in the VLPFC and in and around the inferior prefrontal sulcus (Deiber et al., 1997; Paus, Petrides, Evans, \& Meyer, 1993; Toni \& Passingham, 1999; Toni et al., 1999). Once again, all the responses in these studies consist just of finger or hand movements. In order to make the correct response, subjects performing a conditional task have to attend to the identity of the visual stimuli presented; this may underlie the recruitment of more ventral parts of the lateral frontal cortex than are recruited by the free selection task. In fact, the region of the prefrontal cortex that is critical for conditional task performance (Figure 5) appears to be almost intermediately situated between the visuallearning and the motor-learning prefrontal regions identified in the previous section (Figure 4).

\section{The Dorsolateral Prefrontal Cortex and the Dorsomedial Frontal Cortex}

Emphasizing the DLPFC's role in motor learning and attention to action helps to distinguish its functional role from that of the VLPFC, but at the same time, it unfortunately highlights the current need to distinguish the functional contributions of the DLPFC and the medial frontal areas, particularly the pre-SMA and the anterior cingulate cortex. One or the other or both of these medial frontal areas are frequently activated by the movement sequence learning tasks (Grafton et al., 1995; Hazeltine et al., 1997; Honda et al., 1998; Jenkins, Brooks, Nixon, Frackowiak, \& Passingham, 1994; Jueptner et al., 1997; Sakai et al., 1998; Toni et al., 1999), the attention to action tasks (Jueptner et al., 1997; Krams et al., 1998; Rushworth et al., in press), and the free selection tasks (Deiber, Honda, Ibanez, Sudato, \& Hallett, 1999; Deiber et al., 1996; Deiber, et al., 1991; Frith et al., 1991; Jahanshahi et al., 1995; Jueptner et al., 1996; Spence et al., 1997; Spence et al., 1998) described above. It may often be difficult to decide which of these two areas has been activated in any given study (Crosson et al., 1999). In reviewing 107 PET studies, Koski and Paus (in press) emphasized the co-occurrence of activity in the DLPFC and the anterior cingulate cortex. The distinct functional contributions of the DLPFC and the medial frontal cortex may be better revealed by methods with a finer temporal resolution than most current human neuroimaging methods, such as a single-unit recording and event-related fMRI, or by interference studies involving permanent lesions or transient disruption with transcranial magnetic stimulation (Hadland et al., 1999).

\section{Conclusions}

It has been argued that it may not be correct to consider the DLPFC and the VLPFC to have distinct roles in spatial and form-related working memory, respectively 
(Figure 1). Instead, the DLPFC and the VLPFC can be usefully considered to have high level roles in tasks that demand novel, nonroutine, or attentionally demanding ways of processing motor or visual information. This argument has been based on a reconsideration of the functions of the temporal and parietal lobes (Milner \& Goodale, 1995), the distinct anatomical connections of the DLPFC and the VLPFC (Figure 3), and a review of neuroimaging, lesion, and single-cell recording studies of visual and motor learning, visual and motor attention, and different types of action selection tasks (Figures 4 and 5).

In some ways, this conclusion echoes a hypothesis put forward by Passingham (1993), before much of the anatomical and neuroimaging data reviewed above had been published. Passingham (1993, p. 208) argued that the VLPFC was "informed about the external context, that is, about the world," whereas the DLPFC was "concerned with the animal itself, its eyes and limbs."

It should be emphasized that the differential specializations of areas are likely to be relative, rather than absolute, when those areas are anatomically interconnected and are required to work in concert to perform certain cognitive tasks. This is not just the case in the lateral prefrontal cortex (Carmichael \& Price, 1996; Pandya \& Yeterian, 1998) but also applies in the case of the dorsal and ventral visual streams (Van Essen \& De Yoe, 1995).

It is possible that this simple framework can be extended to accommodate other findings concerning the prefrontal cortex's role in more complex tasks. For example, the ability to combine and manipulate movement elements into numerous possible sequences is an important feature of primate motor behavior, and both the human and the monkey DLPFC is important for the learned production of movement sequences (Barone \& Joseph, 1989; Grafton et al., 1995; Hazeltine et al., 1997; Honda et al., 1998; Jenkins et al., 1994; Jueptner et al., 1997; Sakai et al., 1998; Toni et al., 1999). It may be that this ability to learn and produce sequences, perhaps originally acquired in the context of motor behavior, has been adapted so that the DLPFC now has a role in combining and manipulating internal representations of items in memory (Owen, 1997; Owen, Doyon, Petrides, \& Evans, 1996; Owen, Evans, \& Petrides, 1996; Petrides, 1995, 1998).

\section{REFERENCES}

Asaad, W. F., Rainer, G., \& Miller, E. K. (1998). Neural activity in the primate prefrontal cortex during associative learning. Neuron, 21, 1399-1407.

BadDEley, A. D., \& Hitch, G. (1974). Working memory. In G. H. Bower (Ed.), The psychology of learning and motivation (Vol. 8, pp. 47-89). New York: Academic Press.

BARONE, P., \& JoSEPH, J. P. (1989). Role of the dorsolateral prefrontal cortex in organizing visually guided behavior. Brain, Behavior, \& Evolution, 33, 132-135.

Bates, J. F., \& Goldman-Rakic, P. S. (1993). Prefrontal connections of medial motor areas in the rhesus monkey. Journal of Comparative Neurology, 336, 211-228.

BAYLIS, L. L., \& GAFFAN, D. (1991). Amygdalectomy and ventromedial prefrontal ablation produce similar deficits in food choice and in simple object discrimination learning for an unseen reward. Experimental Brain Research, 86, 61 7-622.

Bechara, A., Damasio, H., Tranel, D., \& Anderson, S. W. (1998). Dissociation of working memory from decision making within the human prefrontal cortex. Journal of Neuroscience, 18, 428-437.

Boussaoud, D., \& Wise, S. P. (1993a). Primate frontal cortex: Effects of stimulus and movement. Experimental Brain Research, 95, 28-40.

Boussaoud, D., \& WisE, S. P. (1993b). Primate frontal cortex: Neuronal activity following attentional versus intentional cues. Experimental Brain Research, 95, 15-27.

Carmichael, S. T., \& Price, J. L. (1995). Sensory and premotor connections of the orbital and medial prefrontal cortex of macaque monkeys. Journal of Comparative Neurology, 363, 642-664.

Carmichael, S. T., \& Price, J. L. (1996). Connectional networks within the orbital and medial prefrontal cortex of macaque monkeys. Journal of Comparative Neurology, 371, 179-207.

Cavada, C., \& Goldman-Rakic, P. S. (1989). Posterior parietal cortex on thesus monkey: II. Evidence for segregated corticocortical networks linking sensory and limbic areas with the frontal lobe. Journal of Comparative Neurology, 287, 422-445.

Chafee, M. V., \& Goldman-RaKic, P. S. (1998). Matching patterns of activity in primate prefrontal area $8 \mathrm{a}$ and parietal area 7 ip neurons during a spatial working memory task. Journal of Neurophysiology, 79, 2919-2940.

Courtney, S. M., Petit, L., Maisog, J. M., Ungerleider, L. G., \& HAXBY, J. V. (1998). An area specialized for spatial working memory in human frontal cortex. Science, 279, 1347-1351.

Crosson, B., SadeK, J. R., Bobholz, J. A., Gokcay, D., Mohr, C. M., Leonard, C. M., Maron, L., Auerbach, E. J., Browd, S. R., FreeMAN, A. J., \& BRIGGS, R. W. (1999). Activity in the paracingulate and cingulate sulci during word generation: An fMRI study of functional anatomy. Cerebral Cortex, 9, 307-316.

Deiber, M.-P., Honda, M., Ibanez, V., Sadato, N., \& Hallett, M. (1999). Mesial motor areas in self-initiated versus externally triggered movements with $\mathrm{MRR}$ : Effect of movement type and rate. Journal of Neurophysiology, 81, 3065-3077.

Deiber, M.-P., Ibanez, V., Sadato, N., \& Hallet, M. (1996). Cerebral structures participating in motor preparation in humans: A positron emission tomography study. Journal of Neurophysiology, 75, 233-247.

Deiber, M.-P., Passingham, R. E., Colebatch, J. G., Friston, K. J., Nixon, P. D., \& Frackowiak, R. S. J. (1991). Cortical areas and the selection of movement: A study with positron emission tomography. Experimental Brain Research, 84, 393-402.

Deiber, M.-P., Wise, S. P., Honda, M., Catalan, M. J., Grafman, J., \& HALLETT, M. (1997). Frontal and parietal networks for conditional motor learning: A positron emission tomography study. Journal of Neurophysiology, 78, 977-991.

Dias, R., RoBbins, T. W., \& RoberTs, A. C. (1996). Dissociation in prefrontal cortex of affective and attentional shifts. Nature, 380, 69-72.

Dum, R. P., \& Strick, P. L. (1991). The origin of corticospinal projections from the premotor areas in the frontal lobe. Journal of Neuroscience, 11, 667-689.

Dum, R. P., \& Strick, P. L. (1993). Cingulate motor areas. In B. A. Vogt \& M. Gabriel (Eds.), Neurobiology of cingulate cortex and limbic thalamus (pp. 415-441). Boston: Birkhauser.

DuM, R. P., \& STRICK, P. L. (1996). Spinal cord terminations of the medial wall motor areas in macaque monkeys. Neuroscience, 16, 6513-6525.

Elliott, R., Frith, C. D., \& Dolan, R. J. (1997). Differential neural responses to positive and negative feedback in planning and guessing tasks. Neuropsychologia, 15, 1395-1404.

Elliott, R., Frith, C. D., \& Dolan, R. J. (1999). Ventromedial prefrontal cortex mediates guessing. Neuropsychologia, 37, 403-411.

FRITH, C. D. (in press). The role of dorsolateral prefrontal cortex in the selection of action, as revealed by functional imaging. Attention and performance.

Frith, C. D., Friston, K. J., Liddle, P. F., \& Frackowiak, R. S. J. (1991). Willed action and the prefrontal cortex in man: A study with PET. Proceedings of the Royal Society of London: Series B, 244, 241 246. 
Fuster, J. M. (1995). Memory in the cerebral cortex: An empirical approach to neural networks in the human and nonhuman primate brain. Cambridge, MA: MIT Press.

Fuster, J. M., Bauer, R. H., \& Jervey, J. P. (1982). Cellular discharge in the dorsolateral prefrontal cortex of the monkey in cognitive tasks. Experimental Neurology, 77, 679-94.

GAFFAN, D. (1994). Interaction of the temporal lobe and frontal lobe in memory. In A.-M. Thierry, J. Glowinski, P. S. Goldman-Rakic, \& Y. Christen (Eds.), Research and perspectives in the neurosciences: Vol. 3. Motor and cognitive functions of the prefrontal cortex (pp. 129139). New York: Springer-Verlag.

Galea, M. P., \& Darian-Smith, I. (1994). Multiple corticospinal neuron populations in the macaque monkey are specified by their unique cortical origins, spinal terminations, and connections. Cerebral Cortex, 4, 166-194.

Goldman, P. S., \& Nauta, W. J. H. (1976). Autoradiographic demonstration of a projection from prefrontal association cortex to the superior colliculus in the rhesus monkey. Brain Research, 116, 145-149.

Goldman-RAKic, P. S. (1987). Circuitry of primate prefrontal cortex and regulation of behaviour by representational memory. In F. Plum \& V. Mountcastle (Eds.), Handbook of physiology: Section 1. The nervous system: Vol. 5. Higher functions of the brain (pp. 373-417). Bethesda, MD: American Physiological Society.

Goldman-RAKIC, P. S. (1998). The prefrontal landscape: Implications of functional architecture for understanding human mentation and the central executive. In A. C. Roberts, T. W. Robbins, \& L. Weiskrantz (Eds.), The prefrontal cortex: Executive and cognitive functions (pp. 87-102). Oxford: Oxford University Press.

Goodale, M. A., \& Milner, A. D. (1992). Separate visual pathways for perception and action. Trends in Neurosciences, 15, 20-25.

Grafton, S. T., Hazeltine, E., \& Ivry, R. (1995). Functional mapping of sequence learning in normal humans. Journal of Cognitive Neuroscience, 7, 497-510.

Hadland, K. A., Rushworth, M. F. S., Passingham, R. E., JahanSHAHI, M., \& RoThWELL, J. (1999). An rTMS comparison of the dorsalateral prefrontal cortex and the pre-SMA in working memory and willed action. Society for Neuroscience Abstracts, 29, 753.5.

Hasegawa, R., Sawaguchi, T., \& Kubota, K. (1998). Monkey prefrontal neuronal activity coding the forthcoming saccade in an oculomotor delayed matching-to-sample task. Journal of Neurophysiology, 79, 322-333.

HaXby, J. V., Horowitz, B., Ungerleider, L. G., Maisog, J. M., Peitrini, P., \& Grady, C. L. (1994). The functional organization of human extrastriate cortex: A PET-rCBF study of selective attention to faces and locations. Journal of Neuroscience, 14, 6336-6353.

Hazeltine, E., Grafton, S. T., \& Ivry, R. (1997). Attention and stimulus characterstics determine the locus of motor-sequencing encoding a PET study. Brain, 120, 123-140.

HE, S. Q., DUM, R. P., \& STRICK, P. L. (1993). Topographic organization of corticospinal projections from the frontal lobe: Motor areas on the lateral surface of the hemispheres. Journal of Neuroscience, 13, 952-980.

HE, S. Q., DuM, R. P., \& STRICK, P. L. (1995). Topographic organization of corticospinal projections from the frontal lobe: Motor areas on the medial surface of the hemisphere. Journal of Neuroscience, 15, 3284-3306.

Honda, M., Deiber, M. P., Ibanez, V., Pascual-Leone, A., Zhuang, P., \& HALLETT, M. (1998). Dynamic cortical involvement in implicit and explicit motor sequence learning: A PET study. Brain, 121, 2159-2173.

Hupe, J. M., James, A. C., PAyne, B. R., \& Lomber, S. G. (1998). Cortical feedback improves discrimination learning between figure and background by V1, V2, and V3 neurons. Nature, 394, 784-787.

Hyder, F., Phelps, E. A., Wiggins, C. J., Labar, K. S., Blamire, A. M., \& Shulman, R. G. (1997). "Willed action": A functional MRI study of the human prefrontal cortex during a sensorimotor task. Proceedings of the National Academy of Sciences, 94, 6989-6994.

Jahanshahi, M., Jenkins, I. H., Brown, R. G., Marsden, C. D., PassINGHAM, R. E., \& BrooKs, D. J. (1995). Self-initiated versus externally triggered movements: I. An investigation using measurement of regional cerebral blood flow with PET and movement-related potentials in normal and Parkinson's disease subjects. Brain, 118, 913933.
Jenkins, I. H., Brooks, D. J., Nixon, P. D., Frackowiak, R. S. J., \& Passingham, R. E. (1994). Motor sequence learning: A study with positron emission tomography. Journal of Neuroscience, 14, 3775-3790.

Jueptner, M., Jenkins, I. H., Brooks, D. J., Frackowiak, R. S. J., \& Passingham, R. E. (1996). The sensory guidance of movement: A comparison of the cerebellum and basal ganglia. Experimental Brain Research, 112, 462-474.

Jueptner, M., Stephan, K. M., Frith, C. D., Brooks, D. J., Frackowiak, R. S. J., \& Passingham, R. E. (1997). Anatomy of motor learning: 1. Frontal cortex and attention to action. Journal of Neurophysiology, 77, 1313-1324.

Konishi, S., NaKajima, K., UChida, I., Kameyama, M., Nakahara, K. SekihaRA, K., \& MiYashita, Y. (1998). Transient activation of inferior prefrontal cortex during cognitive set shifting. Nature Neuroscience, 1, 80-84.

KoskI, L., \& PAUS, T. (in press). Functional connectivity of the anterior cingulate cortex within the human frontal lobe: A brain-mapping metaanalysis. Experimental Brain Research.

Krams, M., Rushworth, M. F. S., Deiber, M. P., Frackowiak, R. S. J., \& PassinghaM, R. E. (1998). The preparation, suppression, and execution of copied movements in the human brain. Experimental Brain Research, 120, 386-398.

LEVy, R., \& GoldMAN-RAKIC, P. S. (1999). Association of storage and processing in the dorsolateral prefrontal cortex of the nonhuman primate. Journal of Neuroscience, 19, 5149-5158.

Lu, M.-T., Preston, J. B., \& STrick, P. L. (1994). Interconnections between the prefrontal cortex and the premotor areas in the frontal lobe. Journal of Comparative Neurology, 341, 375-392.

Luppino, G., Govoni, P., \& Matelli, M. (1998). Prefrontal and cingulate afferents to the rostral premotor areas in the macaque monkey. Society for Neuroscience Abstracts, 24, 257.11.

Matelli, M., Camarda, R., Glickstein, M., \& Rizzollatti, G. (1986). Afferent and efferent projections of the inferior area 6 in the macaque monkey. Journal of Comparative Neurology, 251, 281-298.

Middleton, F. A., \& STRICK, P. L. (1998). Cerebellar output: Motor and cognitive channels. Trends in Cognitive Sciences, 2, 348-354.

Milner, A. D., \& Goodale, M. A. (1995). The visual brain in action (Oxford Psychology Series 27). Oxford: Oxford University Press.

Morecraft, R. J., \& VAN Hoesen, G. W. (1993). Frontal granular cortex input to the cingulate (M3), supplementary (M2) and primary (M1) motor cortices in the rhesus monkey. Journal of Comparative Neurology, 337, 669-689.

Murray, E. A., \& BusSEy, T. J. (1999). Perceptual-mnemonic functions of the perirhinal cortex. Trends in Cognitive Sciences, 3, 142-151.

MurRay, E. A., BusSEY, T. J., \& WISE, S. P. (in press). Role of prefrontal cortex in a network for arbitrary visuomotor mapping. Experimental Brain Research.

O'Scalaidhe, S. P., Wilson, F. A. W., \& Goldman-Rakic, P. S. (1997). Areal segregation of face processing neurons in prefrontal cortex. Science, 278, 1135-1138.

O'Scalaidhe, S. P., Wilson, F. A. W., \& Goldman-RaKic, P. S. (1999) Face selective processing during passive viewing and working memory performance of rhesus monkeys: Evidence for intrinsic specialization of neuronal coding. Cerebral Cortex, 9, 459-475.

OWEN, A. M. (1997). The functional organization of working memory processes within human lateral frontal cortex: The contribution of functional neuroimaging. European Journal of Neuroscience, 7, 13291339.

Owen, A. M., Doyon, J., Petrides, M., \& Evans, A. C. (1996). Planning and spatial working memory: A positron emission tomography study in humans. European Journal of Neuroscience, 8, 353-364.

Owen, A. M., Evans, A. C., \& Petrides, M. (1996). Evidence for a two-stage model of spatial working memory processing within the lateral frontal cortex: A positron emission tomography study. Cerebral Cortex, 6, 31-38.

Pandya, D. N., \& Yeterian, E. H. (1998). Comparison of prefrontal architecture and connections. In A. C. Roberts, T. W. Robbins, \& L. Weiskrantz (Eds.), The prefrontal cortex: Executive and cognitive functions (pp. 51-66). Oxford: Oxford University Press.

Parker, A., \& Gaffan, D. (1998). Memory after frontal/temporal dis- 
connection in monkeys: Conditional and non-conditional tasks, unilateral and bilateral frontal lesions. Neuropsychologia, 36, 259-271.

Passingham, R. E. (1972). Visual discrimination learning after selective prefrontal ablations in monkeys (Macaca mulatta). Neuropsychologia, 10, 27-39.

Passingham, R. E. (1978). Information about movements in monkeys (Macaca mulatta) with lesions of dorsal prefrontal cortex. Brain Research, 152, 313-328.

PASsingham, R. E. (1993). The frontal lobes and voluntary action. Oxford: Oxford University Press.

Passingham, R. E., Toni, I., \& Rushworth, M. F. S. (in press). Specialization within the prefrontal cortex: the ventral prefrontal cortex and associative learning. Experimental Brain Research.

Paus, T., Petrides, M. J., Evans, A. C., \& Meyer, E. (1993). Role of the human anterior cingulate cortex in the control of oculomotor, manual, and speech responses: A positron emission tomography study. Journal of Neurophysiology, 70, 453-469.

Perenin, M.-T., \& Vighetto, A. (1988). Optic ataxia: A specific disruption in visuomotor mechanisms: I. Different aspects of the deficit in reaching for objects. Brain, 111, 643-674.

Petersson, K. M., Elfgren, C., \& Ingvar, M. (1999). Dynamic changes in the functional anatomy of the human brain during recall of abstract designs related to practise. Neuropsychologia, 37, 567-587.

Petrides, M. (1995). Impairments of nonspatial self-ordered and externally ordered working memory tasks after lesions of the mid-dorsal part of the lateral frontal cortex in the monkey. Journal of Neuroscience, 15, 359-373.

Petrides, M. (1998). Specialized systems for the processing of mnemonic information within the primate frontal cortex. In A. C. Roberts, T. W. Robbins, \& L. Weiskrantz (Eds.), The prefrontal cortex: Executive and cognitive functions (pp. 103-116). Oxford: Oxford University Press.

Petrides, M., \& Pandya, D. N. (1984). Projections to the frontal cortex from the posterior parietal region in the rhesus monkey. Journal of Comparative Neurology, 228, 105-116.

Poldrack, R. A., Desmond, J. E., Glover, G. H., \& Gabrieli, J. D. E. (1998). The neural basis of visual skill learning: An fMRI study of mirror reading. Cerebral Cortex, 8, 1-10.

Rainer, G., AsaAd, W. F., \& Miller, E. K. (1998a). Memory fields of neurons in the primate prefrontal cortex. Proceedings of the National Academy of Sciences, 95, 15003-15013.

Rainer, G., AsaAd, W. F., \& Miller, E. K. (1998b). Selective representation of relevant information by neurons in the primate prefrontal cortex. Nature, 393, 577-579.

RAO, S. R., Rainer, G., \& Miller, E. K. (1997). Integration of what and where in the primate prefrontal cortex. Science, 276, 821-823.

ROBERTS, A. C. (1996). Comparison of cognitive function in human and non-human primates. Cognitive Brain Research, 3, 319-327.

Roberts, A. C., Robbins, T. W., \& Weiskrantz, L. (EDs.) (1998). The prefrontal cortex: Executive and cognitive functions. Oxford: Oxford University Press.

RoLls, E. T. (1999). The brain and emotion. Oxford: Oxford University Press.

Rushworth, M. F. S., Krams, M., \& Passingham, R. E. (in press). Complementary lateralization of attention and intention in the human brain: A PET study. Journal of Cognitive Neuroscience.

Rushworth, M. F. S., Nixon, P. D., Eacott, M. J., \& Passingham, R. E. (1997). Ventral prefrontal cortex is not essential for working memory. Journal of Neuroscience, 17, 4829-4838.

Rushworth, M. F. S., Nixon, P. D., \& Passingham, R. E. (1997). The parietal cortex and movement: I. Movement selection and reaching. Experimental Brain Research, 117, 292-310.

Rushworth, M. F. S., \& OWEN, A. M. (1998). The functional organization of the lateral frontal cortex: Conjecture or conjuncture in the electrophysiology literature? Trends in Cognitive Sciences, 2, 46-53.

SAKAGAMI, M., \& NIKI, H. (1994). Encoding of behavioral significance of visual stimuli by primate prefrontal neurons: Relation to relevant task conditions. Experimental Brain Research, 97, 423-436.

Sakai, K., Hikosaka, O., Miyauchi, S., Takino, R., Sasaki, Y., \& PuTZ, B. (1998). Transition of brain activation from frontal to parietal areas in visuomotor sequence learning. Journal of Neuroscience, 18, 1827-1840.
Sakata, H., Taira, M., Kusunoki, M., Murata, A., Tsutsui, K., Tanaka, Y., Shein, W. N., \& MiYashita, Y. (1999). Neural representation of three dimensional features of manipulation objects with stereopsis. Experimental Brain Research, 128, 160-169.

Schall, J. D., Morel, A., King, D. J., \& Bullier, J. (1995). Topography of visual cortex connections with frontal eye field in macaque: Convergence and segregation of processing streams. Journal of Neuroscience, 15, 4464-4487.

Schiltz, C., Bodart, J. M., Dubois, S., Dejardin, S., Michel, C., Roucoux, A., Crommelinck, M., \& Orban, G. A. (1999). Neuronal mechanisms of perceptual learning: Changes in human brain activity with training in orientation discrimination. Neurolmage, 9, 46-62.

SchmahmanN, J. D., \& PandYa, D. N. (1997). The cerebrocerebellar system. In J. D. Schmahmann (Ed.), The cerebellum and cognition (pp. 31-60). San Diego: Academic Press.

Sereno, A. B., \& Maunsell, J. H. R. (1998). Shape selectivity in primate lateral intraparietal cortex. Nature, 395, 500-502.

Spence, S. A., Brooks, D. J., Hirsch, S. R., Liddle, P. F., Meehan, J., \& GRASBY, P. M. (1997). A PET study of voluntary movement in schizophrenic patients experiencing passivity phenomena (delusions of alien control). Brain, 120, 1997-2011.

SPEnCE, S. A., Hirsch, S. R., Brooks, D. J., \& Grasby, P. M. (1998). Prefrontal cortex activity in people with schizophrenia and control subjects: Evidence from positron emission tomography for remission of 'hypofrontality' with recovery from acute schizophrenia. British Journal of Psychiatry, 172, 316-323.

STUPHORN, V., HoffMANN, K. P., \& Miller, L. E. (1999). Correlation of primate superior colliculus and reticular formation discharge with proximal limb muscle activity. Journal of Neurophysiology, 81, 19781982.

Suzuki, W. A., Zola-Morgan, S., Squire, L. R., \& Amaral, D. G. (1993). Lesions of the perirhinal and parahippocampal cortices in the monkey produce long-lasting memory impairments in the visual and tactual modalities. Journal of Neuroscience, 13, 2430-2451.

Toni, I., \& Passingham, R. E. (1999). Prefrontal-basal ganglia pathways are involved in the learning of visuomotor associations: A PET study. Experimental Brain Research, 127, 19-32.

Toni, I., Schluter, N. D., Josephs, O., Friston, K., \& Passingham, R. E. (1999). Signal-, set- and movement-related activity in the human brain: An event-related fMRI study. Cerebral Cortex, 9, 35-49.

UNGERLEIDER, L. G., \& MishKIN, M. (1982). Two cortical visual systems. In D. J. Ingle, M. A. Goodale, \& R. J. W. Mansfield (Eds.), Analysis of visual behaviour (pp. 549-586). Cambridge, MA: MIT Press.

VAN EsSEN, D. C., \& DE YOE, E. A. (1995). Concurrent processing in the visual cortex. In M. S. Gazzaniga (Ed.), The cognitive neurosciences (pp. 383-400). Cambridge, MA: MIT Press.

Van Hoesen, G. W., Morecraft, R. J., \& Vogt, B. A. (1993). Connections of the monkey cingulate cortex. In B. A. Vogt \& M. Gabriel (Eds). Neurobiology of cingulate cortex and limbic thalamus (pp.249284). Boston: Birkhauser.

Walsh, V., Ashbridge, E., \& Cowey, A. (1998). Cortical plasticity in perceptual learning demonstrated by transcranial magnetic stimulation. Neuropsychologia, 36, 45-49.

Webster, M. J., BacheVAlier, J., \& UNGerleider, L. G. (1994). Connections of inferior temporal areas TEO and TE with parietal and frontal cortex in macaque monkeys. Cerebral Cortex, 4, 470-483.

Werner, W., Hoffmann, K. P., \& Dannenberg, S. (1997). Anatomical distribution of arm-movement-related neurons in the primate superior colliculus and underlying reticular formation in comparison with visual and saccadic cells. Experimental Brain Research, 115, 206-216.

WhITE, I. M., \& WISE, S. P. (1999). Rule-dependent neuronal activity in the prefrontal cortex. Experimental Brain Research, 126, 315-335.

Wilson, F. A., O'SCalaidhe, S. P., \& Goldman-Rakic, P. S. (1993). Dissociation of object and spatial processing domains in primate prefrontal cortex. Science, 260, 1955-1958.

YounG, M. P. (1992). Objective analysis of the topological organization of the primate visual cortex. Nature, 358, 152-155.

(Manuscript received October 14, 1999; revision accepted for publication May 2, 2000.) 